 \\ Organized ar
}

\section{Nomograms for General Long-Time Frequency Allocation}

Nomogram A shows approximate upper and lower limits of the optinum working frequency for use at any time over various distances up to 3000 miles. Nomogram B shows the relation between the lowest useful high frequency for l-kw phone communication and that for other powers, phone and CW: this also is for distances up to 3000 miles. The se nomogram apply for any time during the years 1943 to 1945 .

A. Optimum Working Frequency Iimitso- Nomogram $A$ is for de termining the limits of variation of the optimum working frequency $\left(0 . w_{0} f_{0}\right)$, which is taken as $15 \%$ below the maximum usable frequency. This nomogram does not give the lowest useful high frequency。

The distance scale is marked "shortest" on the side pertaining to the lower limit of the o.wof. because, for glven ionogphere conditions, the o.wof. will be less for the shorter distances: it is marked "Ionge on the other side becaus the oowof. is greater for the longer distances.

The mothod of use is as follow:

If a etralghtedge $\mathrm{s}$ placed 80 as to allgn the latitude of the midpotat of the tronsmission path on the left latitude line with the distance be= tween transmitier and receiver, the lower limit of the optimum workeng frequeney for the path will be indicated.

If amilarly, the traightedge is placed so as to allgm the lati:= tude of the widpoint on the latitude Ine at the right with the trand mission distance, the upper limit of the optimum working irequency will be indicated.

Frequeney allocation for the path chosen should be made betwen the se imits.

Examples of use of Homogram do

(1) A transmission path is 1900 mile long and itg matpoint lies as latftude 100 S。 From the nomogram the upper limit of optrmum working ire queney is $22.5 \mathrm{Mc}$ and the lower limit is $6.2 \mathrm{Mc}$.

(2) A group of stations is centered abous latitude $200 \mathrm{~N}$. The maxi mum distance botween stations is 2200 mileg, and the minimum distance

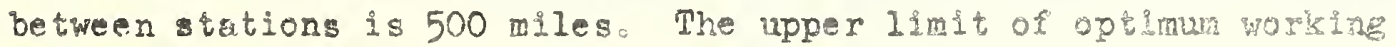




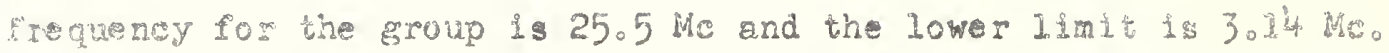

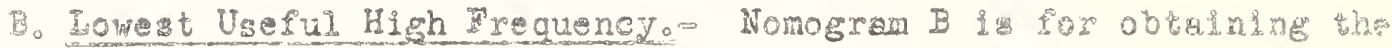
sohofou for distances up to 3000 males. for any power phone or cho

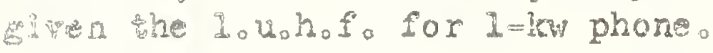

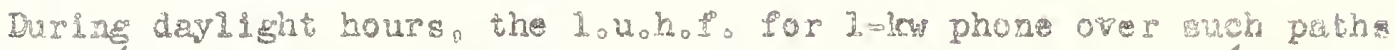

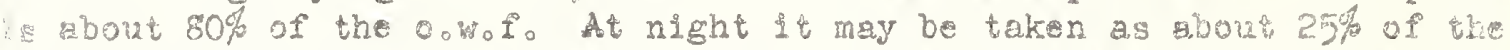

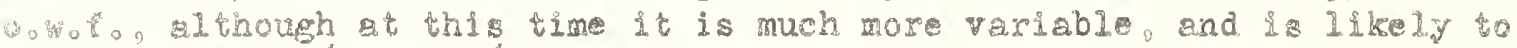
siry between $20 \%$ and $35 \%$ of the $0 . \% \%$

7he romogram $B$ will not give very good results ff the 1.u,bof。 fot

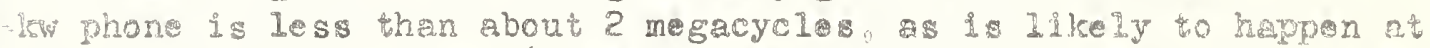

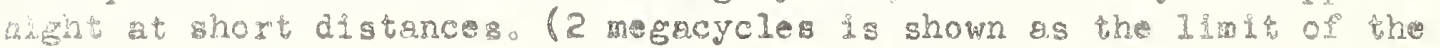
romogram for l-kr phone). In this case the lou,hofofor any pow h gido likely to be less than 2 megacycles.

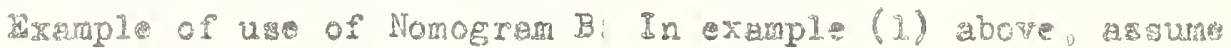

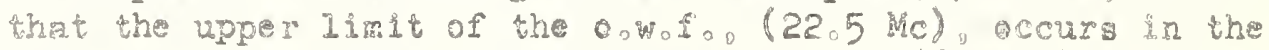

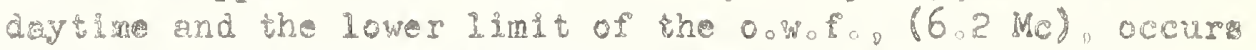

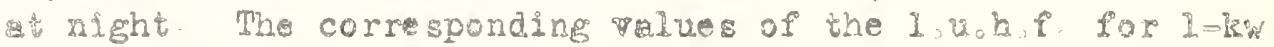
phone are -

$$
\begin{array}{r}
80 \% \times 22.5 \mathrm{Mc}=18.0 \mathrm{Mc} \\
25 \% \mathrm{H} .2 \mathrm{MC}
\end{array}
$$

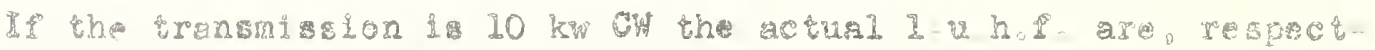

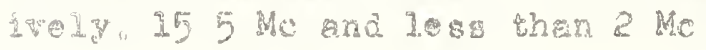

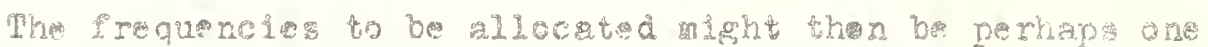
aromad 16 Me ore oround $6 \mathrm{Me}$, and on in betwe 1. Me 
Lowest Useful

High Frequency

(MC)

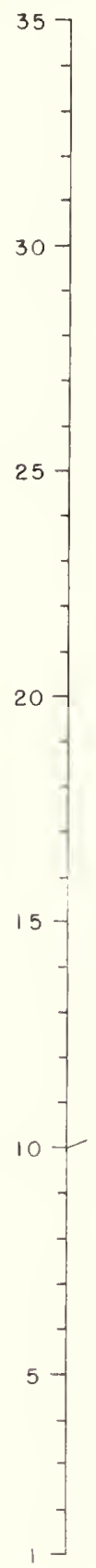

$$
\begin{aligned}
& \text { Lowest Useful } \\
& \text { High Frequency } \\
& \text { for } 1 \text { - kw Phone } \\
& \text { (MC) }
\end{aligned}
$$

Radiated Pawer,

Kilowatts

Phone

CW

0.017

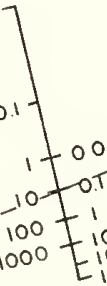

Eiooo
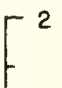

$-5$
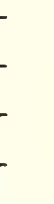

$-10$

shown by

deshed lines.

I kw phone I.u h.f. $=11.5 \mathrm{Mc}$

Power $=10 \mathrm{kw}$ Phone

Actual I.u.h. $=10 \mathrm{Me}$

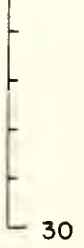

